\title{
Graphene growth from polymers
}

\author{
Hong-Kyu Seo and Tae-Woo Lee \\ Department of Materials Science and Engineering, Pohang University of Science and Technology, Pohang 790-784, Korea
}

\section{Article Info}

Received 2 May 2013

Accepted 30 June 2013

*Corresponding Author

E-mail: twlee@postech.ac.kr

Tel: +82-54-279-2151

\section{Open Access}

DOI: http://dx.doi.org/

10.5714/CL.2013.14.3.145

This is an Open Access article distributed under the terms of the Creative Commons Attribution Non-Commercial License (http://creativecommons.org/licenses/ by-nc/3.0/) which permits unrestricted non-commercial use, distribution, and reproduction in any medium, provided the original work is properly cited.

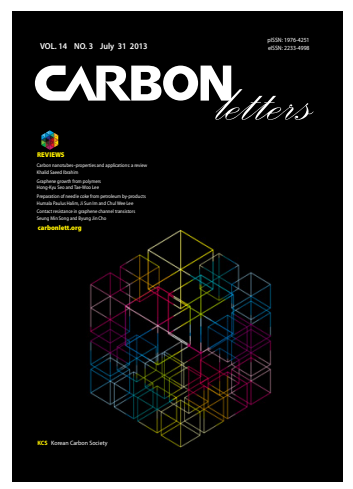

http://carbonlett.org

pISSN: 1976-4251

elSSN: 2233-4998

Copyright $\odot$ Korean Carbon Society

\begin{abstract}
Graphene is a fascinating material with excellent electrical, optical, mechanical, and chemical properties. Remarkable progress has been made in the development of methods for synthesizing large-area, high-quality graphene. Recently, the chemical vapor deposition method has opened up the possibility of using graphene for electronic devices and other applications. This review covers simple and inexpensive methods to grow graphene using polymers as solid carbon sources; which do not require an additional process to transfer graphene from the growth substrate to the receiver substrate.
\end{abstract}

Key words: graphene, graphene synthesis, solid carbon sources, polymers

\section{Introduction}

Graphene [1], a two-dimensional (2D) crystalline monolayer sheet of $s p^{2}$-bonded carbon atoms arranged in a honeycomb lattice, has attracted great interest after its outstanding electrical [2,3], mechanical [4], and chemical [5] properties were revealed when it was obtained for the first time experimentally in 2004 through mechanical exfoliation (the "scotch tape" method) [6].

Most of the reported methods for synthesizing graphene sheets can be divided into three categories: exfoliation, epitaxial growth, and chemical vapor deposition (CVD). Among the exfoliation methods, besides mechanical exfoliation, chemical exfoliation [7-10] is widely used because it is inexpensive and does not require the transfer of graphene from the growth substrate to other substrates. Furthermore, this method allows for the rapid production of relatively large quantities of graphene. The epitaxial method, which utilizes substrates such as $\mathrm{SiC}$ [11] at high temperatures, and the CVD method, which uses $\mathrm{CH}_{4}$ as a gaseous carbon source with nickel $[12,13]$ or copper $[14,15]$ metal as the catalyst substrate, have been used to grow high quality graphene with relatively large areas.

\section{Graphene growth from polymers}

Recently, CVD has been identified as the most suitable way to obtain graphene with the high transmittance and electrical conductivity of particular interest for electronic devices [12-14,16-20]. However, despite its numerous advantages, the CVD method involves some significant challenges. First, an additional process is required to physically transfer graphene films from the catalyst metal to the receiver substrate. During the transfer process, special care should be taken to avoid degradation of the graphene quality, which in turn may cause performance degradation of the devices in which it is used. Furthermore, the use of explosive hydrocarbon gases as a carbon source, and the limit on film size set by the need to transfer the graphene films after growth, are major obstacles for mass production. Although the use of solid carbon sources for the synthesis of graphene is uncommon, there have been some recent reports of such usage [21-25]. Active research is now in progress to find a promising way to overcome the obstacles of the CVD method. The present review covers the growth of graphene from polymers; using the various solid carbon sources available. 
(a)

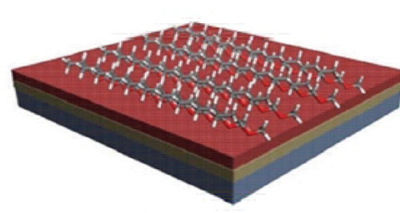

$\mathrm{PMMA} / \mathrm{Cu} / \mathrm{SiO}_{2} / \mathrm{Si}$

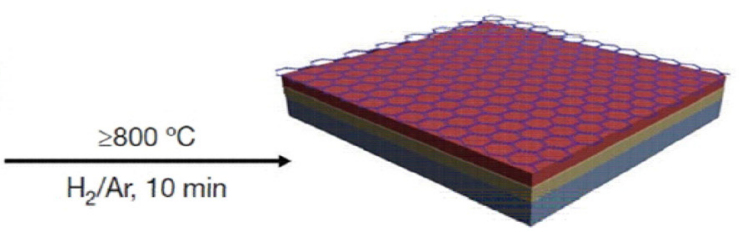

Graphene/Cu/SiO$/ 2 / S i$
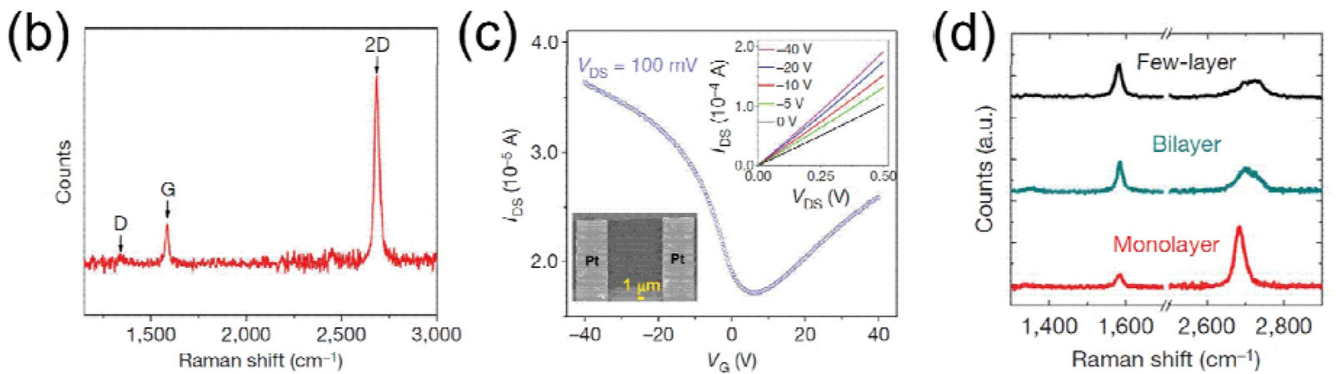

Fig. 1. (a) Monolayer graphene is made by spin-coating and annealing solid poly(methyl methacrylate) (PMMA) films on $\mathrm{Cu}$ substrates at 800 to $1000^{\circ} \mathrm{C}$ under an Ar- $\mathrm{H}_{2}$ gas mix; (b) Raman spectrum (514-nm excitation) of PMMA-derived graphene annealed at $1000^{\circ} \mathrm{C}$; (c) $I_{\mathrm{DS}}-V_{\mathrm{G}} \mathrm{Curve}$ of a PMMA-derived, graphenebased, back-gated field-effect transistor device (at room temperature). The top inset shows the $I_{D S}-V_{D S}$ characteristics; $V_{G}$ changes from $0 \mathrm{~V}$ to $-40 \mathrm{~V}$. The bottom inset shows a scanning electron microscopy (JEOL-6500 microscope) image of the device in which the PMMA-derived graphene is perpendicular to the Pt leads. (IDS: drain-source current; $V_{G}$ : gate voltage; $V_{D S}$ : drain-source voltage); (d) Raman spectra varied by the number of sheets of PMMA-derived graphene with controllable thicknesses derived from different flow rates of $\mathrm{H}_{2}$ [26] (Reprinted with permission. Copyright 2010, Macmillan Publishers Limited).

\subsection{Polymer-sourced graphene grown on metal film}

In order to synthesize large-area, high-quality graphene with controllable thickness, Sun et al. [26] used polymer films deposited on metal catalyst substrates. A spin-coated poly(methyl methacrylate) (PMMA) thin film $(\sim 100 \mathrm{~nm})$ was used as the first solid carbon source. Copper was used as the metal catalyst substrate for the growth of a graphene-monolayer by surface adsorption, because of its low carbon solubility [14,15,27]. A single uniform layer of graphene was obtained by annealing the samples at temperatures from 800 to $1000^{\circ} \mathrm{C}$ for $10 \mathrm{~min}$, under a reductive gas flow $\left(\mathrm{Ar}-\mathrm{H}_{2}\right)$ and low-pressure (Fig. 1a). For further characterization, the graphene films grown were then transferred to various substrates. Fig. 1b shows the Raman spectrum of PMMA-derived graphene, which indicates that it was grown as a monolayer. The electrical properties of the PMMA-derived graphene were evaluated using back-gated (200-nm $\mathrm{SiO}_{2}$ layer), graphene-based, field-effect transistor (FET) devices. The estimated carrier (hole) mobility was $\sim 410$ $\mathrm{cm}^{2} \mathrm{~V}^{-1} \mathrm{~s}^{-1}$ at room temperature, and the "on/off" current ratio was $\sim 2$ (Fig. 1c). These researchers found that the thickness of PMMA-derived graphene could be controlled by changing the $\mathrm{Ar}-\mathrm{H}_{2}$ gas flow rate (Fig. 1d). These were very significant results because the thickness of graphene is strongly related to its electronic properties [28]. When the $\mathrm{H}_{2}$ flow rate was 3-5, 10 , and $50 \mathrm{STP} \mathrm{cm}^{3} \mathrm{~min}^{-1}$ or higher; a few layers, a bilayer, and a monolayer of graphene were formed on the $\mathrm{Cu}$ substrate, respectively, at $1000^{\circ} \mathrm{C}$ under an Ar flow of $500 \mathrm{STP} \mathrm{cm}^{3} \mathrm{~min}^{-}$ 1. They explained that the $\mathrm{H}_{2}$ gas played the role of reducing reagent and carrier to remove carbon atoms from PMMA during growth. A slower $\mathrm{H}_{2}$ flow left more carbon atoms for the formation of thicker layers.

\subsection{Polymer-sourced graphene grown directly on insulating substrate}

To avoid the physical transfer of the new graphene films from the metal catalyst to other inert substrates, Byun et al. [29] introduced an unprecedented direct growth method that allowed for the synthesis of graphene sheets from common polymers such as polystyrene (PS), polyacrylonitrile (PAN), and PMMA using metal capping layers (Fig. 2a). A film consisting of a few layers of graphene was obtained by capping the polymer films with a Ni layer, and then heating them in a high-temperature furnace, in the presence of by $\mathrm{Ar}-\mathrm{H}_{2}$ gas under low vacuum (Fig. 2b). When the polymers were heated to a temperature of $1000^{\circ} \mathrm{C}$, above the distinct thermal decomposition temperature $T_{\mathrm{d}}$ (PS: $\sim 300^{\circ} \mathrm{C}$; PAN: $\sim 235^{\circ} \mathrm{C}$; PMMA: $\sim 310^{\circ} \mathrm{C}$ ), cyclization of $\mathrm{C}-\mathrm{C}$ bonds occurred from the dissociation of other chemical bonds. Fig. 2c shows the formation of graphenes on top of the Ni film $(50 \mathrm{~nm})$ from the PAN film $(10 \mathrm{~nm})$, which was consistent with the Raman spectrum of graphenes grown by CVD [12- 14,16-20]. A comparison with CVD-grown graphenes suggested that the graphene grown from PAN consisted of approximately three layers. Two distinct peaks appeared at $1586 \mathrm{~cm}^{-1}$ (Gband) and $2705 \mathrm{~cm}^{-1}$ (2D-band), and this was consistent with the high-resolution transmission electron microscopy (HRTEM) results, which suggested the presence of three to five layers (Figs. 2d and e). The full width at half maximum (FWHM) of the 2D-band was $\sim 89$ $\mathrm{cm}^{-1}$, similar to that of the 2D-band from CVD-grown, three-layer graphene $\left(\sim 82 \mathrm{~cm}^{-1}\right)$. This result implied that the dissociated carbon atoms, or aliphatic molecules, generated by pyrolysis diffused into the Ni layer at $1000^{\circ} \mathrm{C}$, and precipitation of carbon occurred at the top surface upon cooling [15]. After removal of the Ni capping layer, similar Raman spectra were observed (Fig. 2f). This meant that the graphene was formed under the Ni capping layer as a result of carbon diffusion into the metal, and that subsequent precipitation as a 
(a)<smiles>C[Al](C(CC(C)(C)C)c1ccccc1)C(C)(C)C</smiles>

PS<smiles>CC(C)C(C=N)CC(C)(C)C</smiles>

PAN

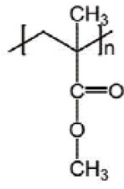

PMMA

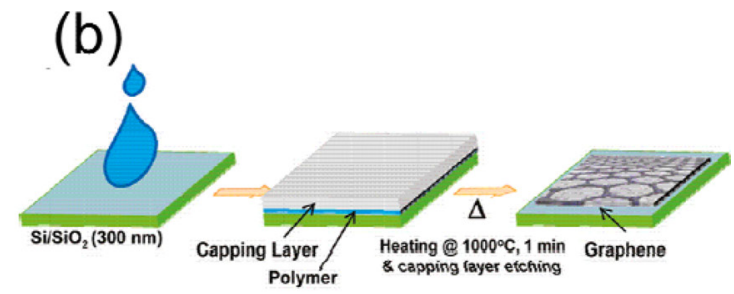

(c)

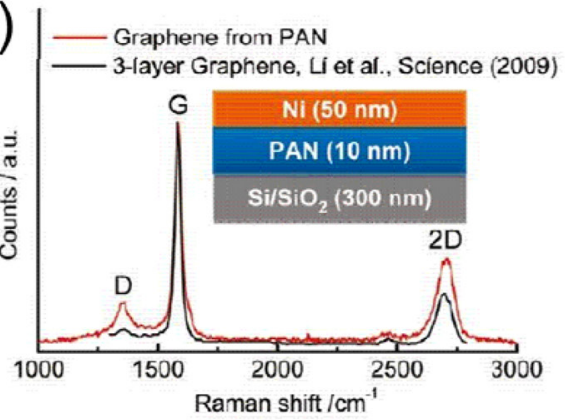

(d)

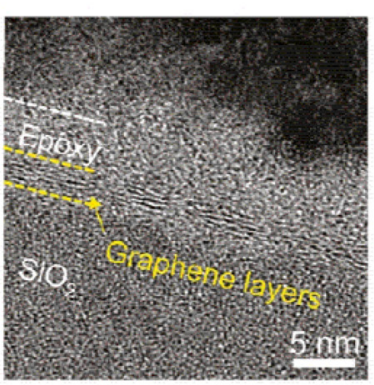

(e)

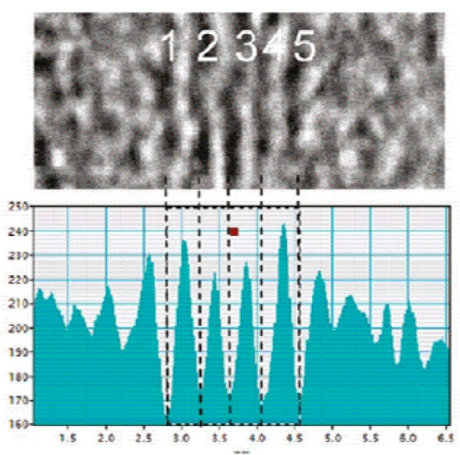

(f)

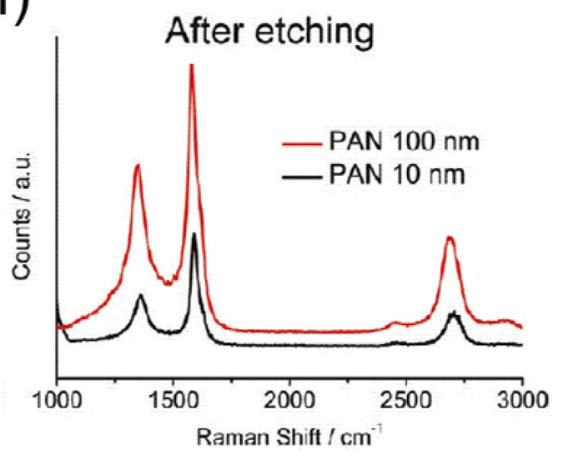

Fig. 2. (a) Chemical structure of polymers used as graphene precursors; (b) graphene growth process; (c) Raman spectra of PAN-derived graphene film with a 50 -nm-thick Ni capping layer annealed at $1000^{\circ} \mathrm{C}$ (the capping layer is subsequently removed); (d) cross-sectional high-resolution transmission electron microscopy (HRTEM) image of graphenes formed on a $\mathrm{SiO}_{2} / \mathrm{Si}$ substrate outside the agglomerated Ni islands; (e) magnified HRTEM image and intensity profile across the graphenes; (f) Raman spectra of PAN-derived graphene with polymer layers of different thickness after removing the capping layer [29] (Reprinted with permission. Copyright 2011, American Chemical Society). PS: polystyrene, PAN: polyacrylonitrile, PMMA: poly(methyl methacrylate).

graphene layer underneath the metal surface.

Unlike monolayer graphene, which has a semi-metal and zeroband-gap electronic structure [30], AB-stacked (Bernal) bilayer graphene has a tunable band gap; while twisted bilayer graphene shows angle-dependent electronic properties [28,31-37]. Thus, bilayer graphene is more attractive for many electronic and optical device applications, and much effort has been focused on the study of bilayer graphene. Yan et al. [38] demonstrated a general, transfer-free method to grow bilayer graphene directly on insulating substrates from polymer films such as poly(2-phenylpropyl) methylsiloxane (PPMS), PMMA, PS, and poly(acrylonitrile-cobutadiene-co-styrene) (ABS). The polymer solution was spincoated onto the substrate and then capped with a $500-\mathrm{nm} \mathrm{Ni}$ layer. Annealing at $1000^{\circ} \mathrm{C}$ under low pressure and a reducing atmosphere resulted in the growth of bilayer graphene, which was transformed from the polymer film under the Ni layer (Fig. 3a). After annealing for 7-20 min, a $1 \mathrm{~cm}^{2}$ homogeneous bilayer of graphene was formed between the $\mathrm{Ni}$ capping layer and the insulating substrate. The etching process, in which the Ni layer was dissolved using Marble's reagent, led to direct growth of bilayer graphene on the insulating substrate, thus eliminating the typical graphene transfer step. Fig. 3 b shows the Raman spectrum of PPMS-derived bilayer graphene, with an FWHM of about 50 $\mathrm{cm}^{-1}$ for the $2 \mathrm{D}$ peak. The Raman spectrum, which had a very low D peak, and the Raman mappings of the $\mathrm{D}$ to $\mathrm{G}$ peak ratio $\left(I_{\mathrm{D}} / I_{\mathrm{G}}\right.$ $<0.1$ ) (Fig. 3c), suggested that high-quality graphene was derived from the PPMS film. The low sheet resistance of about $1000 \Omega$ also confirmed the high quality of the graphene film. Raman mapping of the $\mathrm{G}$ to $2 \mathrm{D}$ peak ratio $\left(I_{\mathrm{G}} / I_{2 \mathrm{D}}\right)$, ranged between 0.7 and 1.3 (Fig. 3d; the blue region denotes bilayer graphene), suggested that bilayer graphene covered about $90 \%$ of the surface. Back-gated, graphene-based, FET devices were fabricated on a 500-nm-thick $\mathrm{SiO}_{2}$ dielectric to evaluate the electrical properties of the PPMSderived graphene. The PPMS-derived graphene FET showed ambipolar behavior and exhibited a carrier (hole) mobility of $\sim 220$ $\mathrm{cm}^{2} \mathrm{~V}^{-1} \mathrm{~s}^{-1}$ at room temperature (Fig. 4a), similar to that of CVDgrown graphene [12-14,26,37,39]. In the CVD method that uses a gaseous source, it is difficult to control the thickness of graphene 
(a)
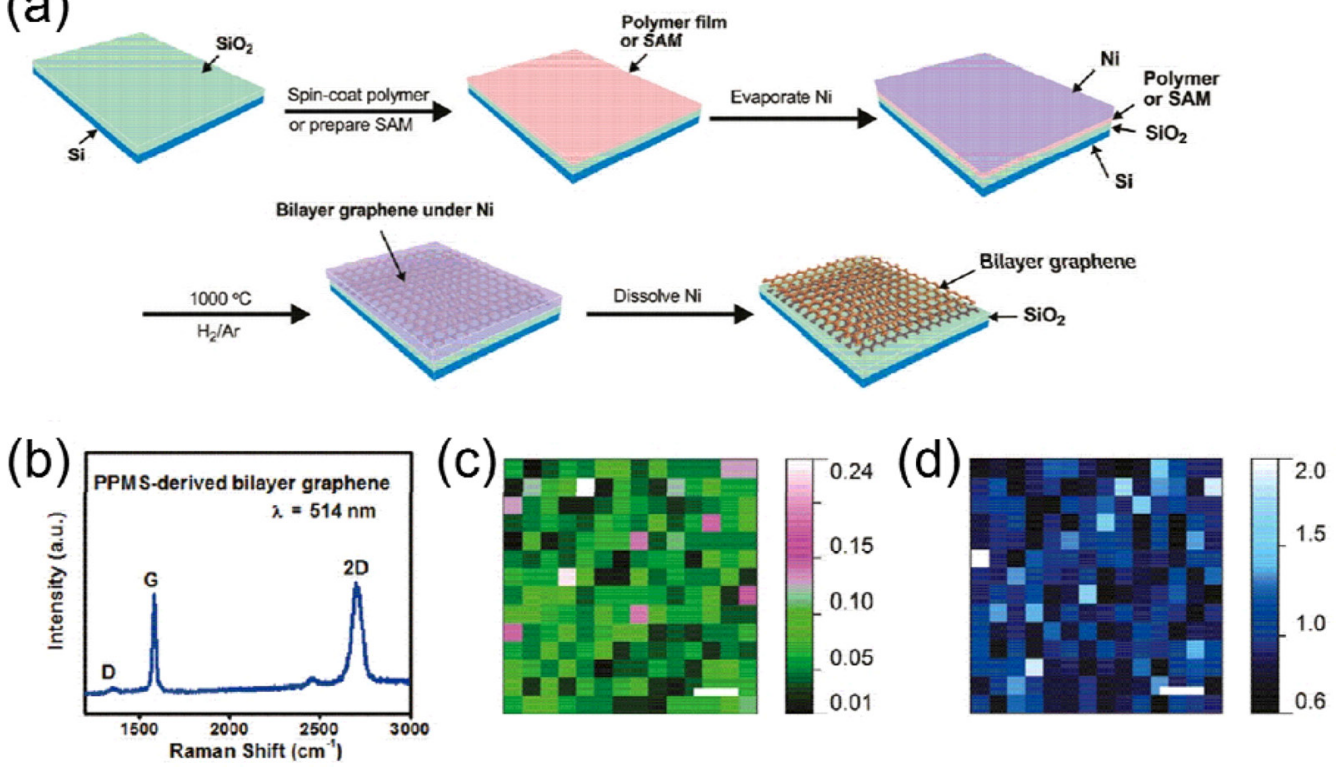

Fig. 3. (a) Bilayer graphene grown directly on a $\mathrm{SiO}_{2} / \mathrm{Si}$ substrate from a solid polymer or self-assembled monolayer (SAM) film by annealing the sample under an Ar- $\mathrm{H}_{2}$ gas mix at $1000^{\circ} \mathrm{C}$ for $15 \mathrm{~min}$; (b) Raman spectrum (514-nm excitation) of PPMS-derived bilayer graphene; two-dimensional (2D) Raman (514 nm) mapping of the bilayer graphene film $\left(112 \times 112 \mu \mathrm{m}^{2}\right)$ : (c) D/G peak ratio; (d) G/2D peak ratio. The color gradient bar is to the right of each map, and the scale bars are equivalent to $20 \mu \mathrm{m}$ in (c) and (d) [38] (Reprinted with permission. Copyright 2011, American Chemical Society). PPMS: poly(2-phenylpropyl)methylsiloxane.
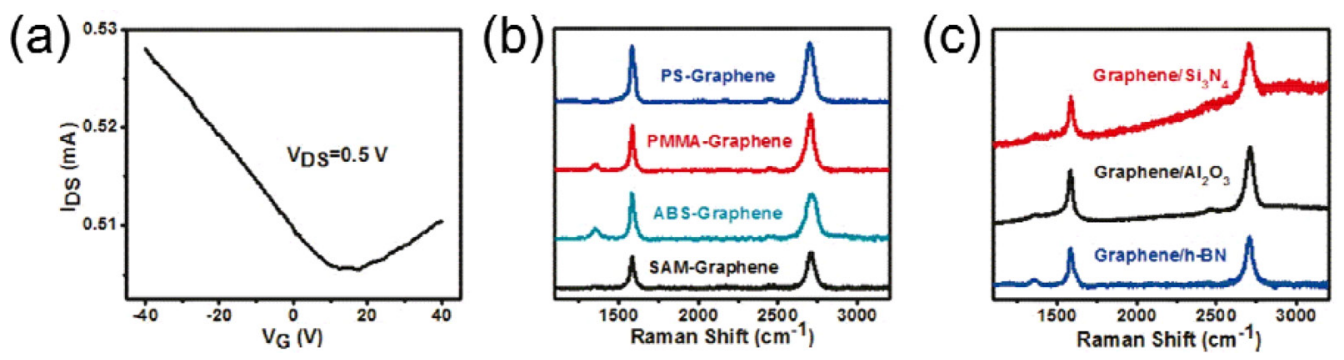

Fig. 4. (a) los- $V_{G}$ curve for a PPMS-derived, graphene-based, back-gated field-effect transistor device (room temperature); (b) Raman spectra of graphene converted from polymers (PS, PMMA, ABS) and an self-assembled monolayer (SAM) prepared from butyltriethoxysilane; (c) Raman spectra of graphene derived from PPMS on h-BN, $\mathrm{Si}_{3} \mathrm{~N}_{4}$, and $\mathrm{Al}_{2} \mathrm{O}_{3}$ (sapphire) [38] (Reprinted with permission. Copyright 2011, American Chemical Society). PS: polystyrene, PMMA: poly(methyl methacrylate), ABS: poly(acrylonitrile-co-butadiene-co-styrene), PPMS: poly(2-phenylpropyl)methylsiloxane.

when employing Ni as a catalyst, owing to the continuous supply of carbon and the high solubility of $\mathrm{Ni}$ in carbon $[12,13]$. In this method, the fact that the amount of feed carbon was limited and fixed between the insulating substrate and the Ni film, facilitated the growth of bilayer graphene. Other polymers-PS, PMMA, and ABS-were also converted to bilayer graphene by the direct growth method on insulating substrates; under the same reaction conditions (Fig. 4b). In addition, bilayer graphene was synthesized on several other insulating substrates such as hexagonal boron nitride (h-BN), $\mathrm{Si}_{3} \mathrm{~N}_{4}$, and $\mathrm{Al}_{2} \mathrm{O}_{3}$ (sapphire) (Fig. 4c).

As another approach to direct growth, Peng et al. [40] placed the polymer films on top of the Ni layer. Bilayer graphene was formed between the insulating substrates and the Ni layers as a result of carbon diffusion through the Ni layer at an elevated temperature [41]. Solid polymer films of PMMA, high-impact PS, or ABS were used as carbon sources, and the samples were annealed under $\mathrm{Ar}-\mathrm{H}_{2}$ gas flow at $1000^{\circ} \mathrm{C}$ for $10 \mathrm{~min}$. The carbon atoms that decomposed from the carbon source diffused into the Ni film at high temperatures and precipitated to form graphene on both sides of the Ni film upon cooling (Fig. 5a). After the Ni layer was removed, bilayer graphene was located directly on the $\mathrm{SiO}_{2}$ substrate. After Ni etching, the Raman spectrum was obtained from the PMMA-derived bilayer graphene on $\mathrm{SiO}_{2}$ (Fig. 5b). The spectrum showed a $\mathrm{G}$ peak at $1580 \mathrm{~cm}^{-1}$ and a $2 \mathrm{D}$ peak at $2700 \mathrm{~cm}^{-1}$, which were comparable in intensity, and the FWHM of the $2 \mathrm{D}$ peak was about $50 \mathrm{~cm}^{-1}$. The small D peak at $1350 \mathrm{~cm}^{-1}$ indicated that the graphene had few defects. The quality of the PMMA-derived graphene was further confirmed by Raman mapping of the $\mathrm{D}$ to $\mathrm{G}$ peak intensity ratio. Over $\sim 99 \%$ of the map showed a ratio below 0.1 (Fig. $5 \mathrm{c}$ ), and four-point probe measurement of the graphene film yielded a sheet resistance of about 2000 $\Omega /$ sq. The comparable intensities of the $\mathrm{G}$ and $2 \mathrm{D}$ peaks (Fig. $5 \mathrm{~b}$ ), and the Raman mapping of the $\mathrm{G}$ to $2 \mathrm{D}$ peak intensity ratio (Fig. 5d), implied that PMMA-derived graphene on $\mathrm{SiO}_{2}$ was bilayered. The PMMA-derived graphene on $\mathrm{SiO}_{2}$ was transferred to a TEM grid and examined using low-resolution TEM (Figs. 6a and b). The results showed two carbon layers, indicating the bilayer characteris- 
(a)

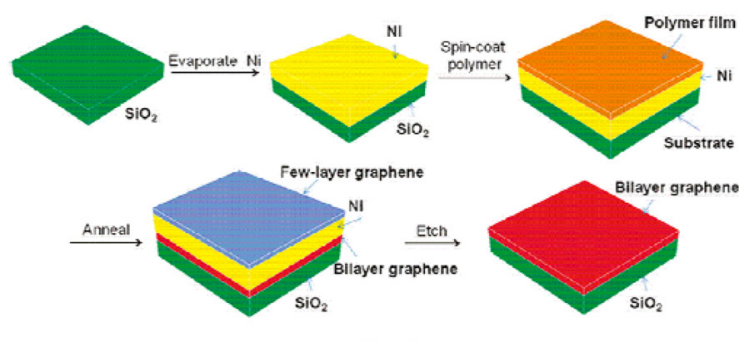

(b)

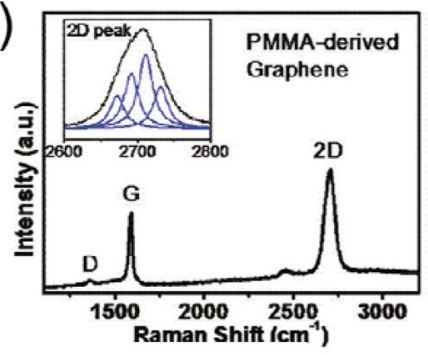

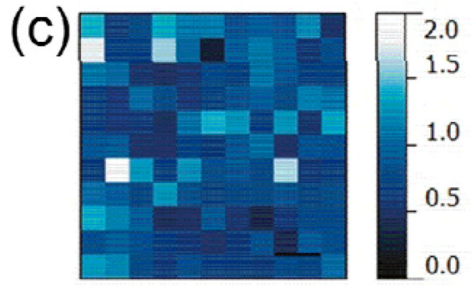

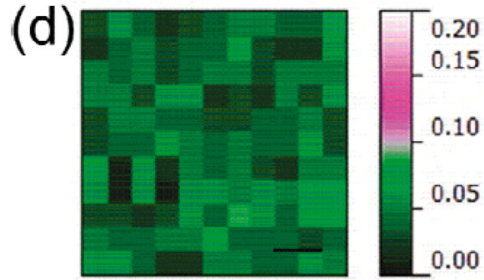

Fig. 5. (a) Schematic of the growth of bilayer graphene from polymer films; bilayer graphene is grown directly on a $\mathrm{SiO}_{2} / \mathrm{Si}$ substrate by spin-coating a polymer film on a Ni layer and annealing the sample under an $\mathrm{Ar}-\mathrm{H}_{2}$ gas mix at $1000^{\circ} \mathrm{C}$ for $10 \mathrm{~min}$; (b) Raman spectrum of PMMA-derived bilayer graphene; Raman mapping of the PMMA-derived bilayer graphene film $\left(100 \times 100 \mu \mathrm{m}^{2}\right)$ : (c) D/G peak ratio; (d) G/2D peak ratio [40] (Reprinted with permission. Copyright 2011, American Chemical Society). PMMA: poly(methyl methacrylate).
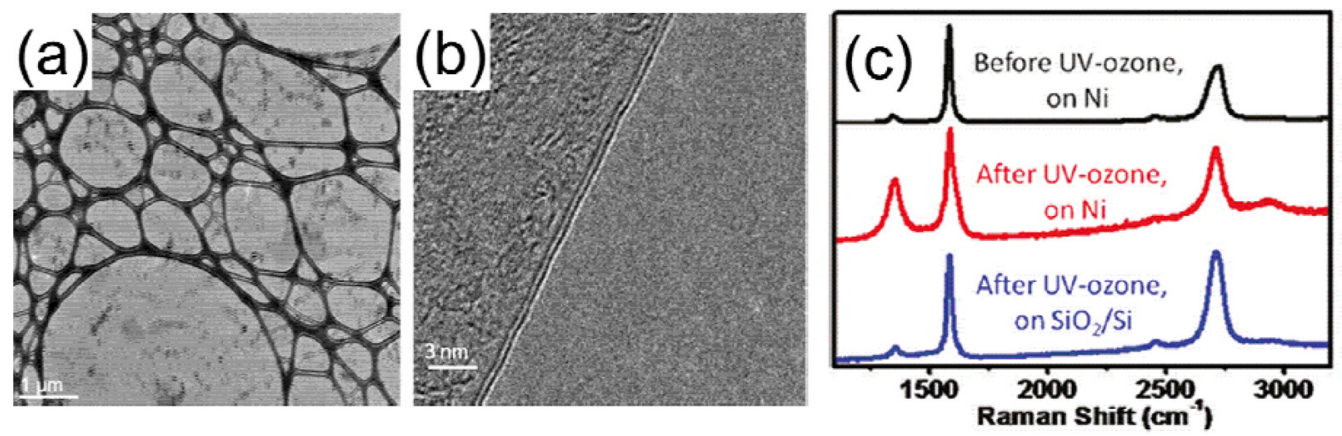

Fig. 6. (a) Low-resolution transmission electron microscopy (TEM) image of bilayer graphene films on a TEM grid; (b) high-resolution TEM image of bilayer graphene edges showing two carbon layers; (c) Raman spectra of graphene: from the top of the Ni layer before and after UV-ozone exposure; on the substrate after UV-ozone exposure and removal of the Ni layer [40] (Reprinted with permission. Copyright 2011, American Chemical Society).

tic of the PMMA-derived graphene film. To prove that the graphene films on $\mathrm{SiO}_{2}$ did not originate from the top side of the Ni layer, the surface of the samples was subjected to UV-ozone treatment for $15 \mathrm{~min}$ (Fig. 6c). Before the UV-ozone treatment, the graphene film showed a small D peak with $I_{\mathrm{D}} / I_{\mathrm{G}}<0.1$. After the UV-ozone treatment, the D peak intensity increased such that $I_{\mathrm{D}} / I_{\mathrm{G}} \approx 0.8$, suggesting severe damage of the graphene film. However, after removing the $\mathrm{Ni}$ film, bilayer graphene that gave a small $\mathrm{D}$ peak was obtained on $\mathrm{SiO}_{2}$, which served as evidence that the bilayer graphene on the $\mathrm{SiO}_{2}$ layer was formed underneath, and not on top of, the Ni film.

\section{Conclusions}

In this review, several graphene synthesis methods using polymers are introduced. In various studies, homogeneous graphene films of large area were obtained. Depending on the film structure, some methods did not require an additional graphene transfer process. These are cost-effective, scalable, and safe ways to grow gra- phene, and hence are suitable for mass production. When compared with conventional CVD-grown graphene, however, the conductivity of polymer-derived graphene needs to be increased beyond its present value for use in graphene-based electronics. Therefore, further research in this area is necessary to provide a promising way to utilize graphene more practically in the near future.

\section{Acknowledgements}

This work was supported under the framework of an international cooperation program managed by National Research Foundation of Korea (2012033187).

\section{References}

[1] Novoselov KS, Jiang D, Schedin F, Booth TJ, Khotkevich VV, Morozov SV, Geim AK. Two-dimensional atomic crystals. Proc Natl 
Acad Sci U S A, 102, 10451 (2005). http://dx.doi.org/10.1073/ pnas.0502848102.

[2] Hwang EH, Adam S, Das Sarma D. Carrier transport in twodimensional graphene layers. Phys Rev Lett, 98, 186806 (2007). http://dx.doi.org/ 10.1103/PhysRevLett.98.186806.

[3] Bolotin KI, Sikes KJ, Jiang Z, Klima M, Fudenberg G, Hone J, Kim P, Stormer HL. Ultrahigh electron mobility in suspended graphene. Solid State Commun, 146, 351 (2008). http://dx.doi. org/10.1016/j.ssc.2008.02.024.

[4] Lee C, Wei XD, Kysar JW, Hone J. Measurement of the elastic properties and intrinsic strength of monolayer graphene. Science, 321, 385 (2008). http://dx.doi.org/10.1126/science.1157996.

[5] Geim AK. Graphene: status and prospects. Science, 324, 1530 (2009). http://dx.doi.org/10.1126/science.1158877.

[6] Novoselov KS, Geim AK, Morozov SV, Jiang D, Zhang Y, Dubonos SV, Grigorieva IV, Firsov AA. Electric field effect in atomically thin carbon films. Science, 306, 666 (2004). http://dx.doi. org/10.1126/science.1102896.

[7] Stankovich S, Dikin DA, Dommett GHB, Kohlhaas KM, Zimney EJ, Stach EA, Piner RD, Nguyen ST, Ruoff RS. Graphenebased composite materials. Nature, 442, 282 (2006). http://dx.doi. org/10.1038/nature04969.

[8] Blake P, Brimicombe PD, Nair RR, Booth TJ, Jiang D, Schedin F, Ponomarenko LA, Morozov SV, Gleeson HF, Hill EW, Geim AK, Novoselov KS. Graphene-based liquid crystal device. Nano Lett, 8, 1704 (2008). http://dx.doi.org/10.1021/n1080649i.

[9] Li X, Zhang G, Bai X, Sun X, Wang X, Wang E, Dai H. Highly conducting graphene sheets and Langmuir-Blodgett films. Nat Nanotechnol, 3, 538 (2008). http://dx.doi.org/10.1038/nnano.2008.210.

[10] Tung VC, Allen MJ, Yang Y, Kaner RB. High-throughput solution processing of large-scale graphene. Nat Nanotechnol, 4, 25 (2009). http://dx.doi.org/10.1038/nnano.2008.329.

[11] Berger C, Song Z, Li X, Wu X, Brown N, Naud C, Mayou D, Li T, Hass J, Marchenkov AN, Conrad EH, First PN, de Heer WA. Electronic confinement and coherence in patterned epitaxial graphene. Science, 312, 1191 (2006). http://dx.doi.org/10.1126/science. 1125925 .

[12] Kim KS, Zhao Y, Jang H, Lee SY, Kim JM, Kim KS, Ahn JH, Kim P, Choi JY, Hong BH. Large-scale pattern growth of graphene films for stretchable transparent electrodes. Nature, 457, 706 (2009). http://dx.doi.org/10.1038/nature07719.

[13] Reina A, Jia X, Ho J, Nezich D, Son H, Bulovic V, Dresselhaus MS, Kong J. Large area, few-layer graphene films on arbitrary substrates by chemical vapor deposition. Nano Lett, 9, 30 (2009). http://dx.doi.org/10.1021/n1801827v.

[14] Li X, Cai W, An J, Kim S, Nah J, Yang D, Piner R, Velamakanni A, Jung I, Tutuc E, Banerjee SK, Colombo L, Ruoff RS. Large-area synthesis of high-quality and uniform graphene films on copper foils. Science, 324, 1312 (2009). http://dx.doi.org/10.1126/science. 1171245 .

[15] Li X, Cai W, Colombo L, Ruoff RS. Evolution of graphene growth on $\mathrm{Ni}$ and $\mathrm{Cu}$ by carbon isotope labeling. Nano Lett, 9, 4268 (2009). http://dx.doi.org/10.1021/n1902515k.

[16] Bae S, Kim H, Lee Y, Xu X, Park JS, Zheng Y, Balakrishnan J, Lei T, Ri Kim H, Song YI, Kim YJ, Kim KS, Ozyilmaz B, Ahn JH, Hong BH, Iijima S. Roll-to-roll production of 30-inch graphene films for transparent electrodes. Nat Nanotechnol, 5, 574 (2010). http://dx.doi.org/10.1038/NNANO.2010.132.

[17] Bhaviripudi S, Jia X, Dresselhaus MS, Kong J. Role of kinetic fac- tors in chemical vapor deposition synthesis of uniform large area graphene using copper catalyst. Nano Lett, 10, 4128 (2010). http:// dx.doi.org/10.1021/nl102355e.

[18] Gao L, Ren W, Zhao J, Ma LP, Chen Z, Cheng HM. Efficient growth of high-quality graphene films on $\mathrm{Cu}$ foils by ambient pressure chemical vapor deposition. Appl Phys Lett, 97, 183109 (2010). http://dx.doi.org/10.1063/1.3512865.

[19] Chae SJ, Gunes F, Kim KK, Kim ES, Han GH, Kim SM, Shin HJ, Yoon SM, Choi JY, Park MH, Yang CW, Pribat D, Lee YH. Synthesis of large-area graphene layers on poly-nickel substrate by CVD: wrinkle formation. Adv Mater, 21, 2328 (2009). http:// dx.doi.org/10.1002/adma.200803016.

[20] Zhang Y, Gomez L, Ishikawa FN, Madaria A, Ryu K, Wang C, Badmaev A, Zhou C. Comparison of graphene growth on singlecrystalline and polycrystalline Ni by chemical vapor deposition. J Phys Chem Lett, 1, 3101 (2010). http://dx.doi.org/10.1021/ jz1011466.

[21] Zheng M, Takei K, Hsia B, Fang H, Zhang X, Ferralis N, Ko H, Chueh YL, Zhang Y, Maboudian R, Javey A. Metal-catalyzed crystallization of amorphous carbon to graphene. Appl Phys Lett, 96, 063110 (2010). http://dx.doi.org/10.1063/1.3318263.

[22] Shin HJ, Choi WM, Yoon SM, Han GH, Woo YS, Kim ES, Chae SJ, Li XS, Benayad A, Loc DD, Gunes F, Lee YH, Choi JY. Transfer-free growth of few-layer graphene by self-assembled monolayers. Adv Mater, 23, 4392 (2011). http://dx.doi.org/10.1002/ adma.201102526.

[23] Seo JH, Kang JW, Kim DH, Jo S, Ryu SY, Lee HW, Kim CS. Simple wafer-scale growth and transfer of graphene film converted from spin-coated fullerene derivative. ECS Solid State Lett, 2, M13 (2013). http://dx.doi.org/10.1149/2.003302ssl.

[24] Perdigao LsMA, Sabki SN, Garfitt JM, Capiod P, Beton PH. Graphene formation by decomposition of $\mathrm{C}_{60}$. J Phys Chem $\mathrm{C}, \mathbf{1 1 5}$, 7472 (2011). http://dx.doi.org/10.1021/jp111462t.

[25] Lee H, Lee S, Hong J, Lee SG, Lee JH, Lee T. Graphene converted from the photoresist material on polycrystalline nickel substrate. Jpn J Appl Phys, 51, 06FD17 (2012). http://dx.doi.org/10.1143/ JJAP.51.06FD17.

[26] Sun Z, Yan Z, Yao J, Beitler E, Zhu Y, Tour JM. Growth of graphene from solid carbon sources. Nature, 468, 549 (2010). http:// dx.doi.org/10.1038/nature09579.

[27] Li X, Magnuson CW, Venugopal A, An J, Suk JW, Han B, Borysiak M, Cai W, Velamakanni A, Zhu Y, Fu L, Vogel EM, Voelkl E, Colombo L, Ruoff RS. Graphene films with large domain size by a two-step chemical vapor deposition process. Nano Lett, 10, 4328 (2010). http://dx.doi.org/10.1021/nl101629g.

[28] Zhang Y, Tang TT, Girit C, Hao Z, Martin MC, Zettl A, Crommie MF, Shen YR, Wang F. Direct observation of a widely tunable bandgap in bilayer graphene. Nature, 459, 820 (2009). http:// dx.doi.org/10.1038/nature08105.

[29] Byun SJ, Lim H, Shin GY, Han TH, Oh SH, Ahn JH, Choi HC, Lee TW. Graphenes converted from polymers. J Phys Chem Lett, 2, 493 (2011). http://dx.doi.org/10.1021/jz200001g.

[30] Castro Neto AH, Guinea F, Peres NMR, Novoselov KS, Geim AK. The electronic properties of graphene. Rev Mod Phys, 81, 109 (2009). http://dx.doi.org/10.1103/RevModPhys.81.109.

[31] McCann E. Asymmetry gap in the electronic band structure of bilayer graphene. Phys Rev B, 74, 161403 (2006). http://dx.doi. org/10.1103/PhysRevB.74.161403.

[32] Oostinga JB, Heersche HB, Liu X, Morpurgo AF, Vandersypen 
LMK. Gate-induced insulating state in bilayer graphene devices. Nat Mater, 7, 151 (2008). http://dx.doi.org/10.1038/nmat2082.

[33] Castro EV, Novoselov KS, Morozov SV, Peres NMR, dos Santos JMBL, Nilsson J, Guinea F, Geim AK, Neto AHC. Biased bilayer graphene: semiconductor with a gap tunable by the electric field effect. Phys Rev Lett, 99, 216802 (2007). http://dx.doi.org/10.1103/ PhysRevLett.99.216802.

[34] Novoselov KS, McCann E, Morozov SV, Fal'ko VI, Katsnelson MI, Zeitler U, Jiang D, Schedin F, Geim AK. Unconventional quantum Hall effect and Berry's phase of $2 \pi$ in bilayer graphene. Nat Phys, 2, 177 (2006). http://dx.doi.org/10.1038/nphys245.

[35] Ohta T, Bostwick A, Seyller T, Horn K, Rotenberg E. Controlling the electronic structure of bilayer graphene. Science, 313, 951 (2006). http://dx.doi.org/10.1126/science.1130681.

[36] Mak KF, Lui CH, Shan J, Heinz TF. Observation of an electricfield-induced band gap in bilayer graphene by infrared spectroscopy. Phys Rev Lett, 102, 256405 (2009). http://dx.doi.org/10.1103/
PhysRevLett.102.256405.

[37] Luican A, Li G, Reina A, Kong J, Nair RR, Novoselov KS, Geim AK, Andrei EY. Single-layer behavior and its breakdown in twisted graphene layers. Phys Rev Lett, 106, 126802 (2011). http://dx.doi. org/10.1103/PhysRevLett.106.126802.

[38] Yan Z, Peng Z, Sun Z, Yao J, Zhu Y, Liu Z, Ajayan PM, Tour JM. Growth of bilayer graphene on insulating substrates. ACS Nano, $\mathbf{5}$, 8187 (2011). http://dx.doi.org/10.1021/nn202829y.

[39] Lee S, Lee K, Zhong Z. Wafer scale homogeneous bilayer graphene films by chemical vapor deposition. Nano Lett, 10, 4702 (2010). http://dx.doi.org/10.1021/nl1029978.

[40] Peng Z, Yan Z, Sun Z, Tour JM. Direct growth of bilayer graphene on $\mathrm{SiO}_{2}$ substrates by carbon diffusion through nickel. ACS Nano, 5, 8241 (2011). http://dx.doi.org/10.1021/nn202923y.

[41] Yu Q, Lian J, Siriponglert S, Li H, Chen YP, Pei SS. Graphene segregated on Ni surfaces and transferred to insulators. Appl Phys Lett, 93, 113103 (2008). http://dx.doi.org/10.1063/1.2982585. 